\title{
PENGARUH PEMBERIAN KOMPRES HANGAT TERHADAP PENURUNAN RASA NYERI PERSALINAN KALA I \\ FASE AKTIF DI BIDAN PRAKTEK MANDIRI YULIA FONNA SKM DESA LIPAH RAYEUK KECAMATAN JEUMPAKABUPATEN BIREUEN TAHUN 2019
}

\section{The Effect Of Giving Warm Compress To The Reduction Of Pain In Maternal Stage I Of Active Phase In The Independent Practical Midwife Yulia Fonna Skm Lipah Rayeuk Village Jeumpa Regency Bireuen District 2019}

\author{
Yolla Asmaul Nufra*1, Azimar² \\ 1. Dosen Akbid Munawarah, J1. Sultan Iskandar Muda No. 18 Kota Juang, Bireuen 24251, Indonesia \\ 2. Mahasiswa Akbid Munawarah, Jl. Sultan Iskandar Muda No. 18 Kota Juang, Bireuen 24251, Indonesia \\ *Korespondensi Penulis : yollaasmaul_nufra@yahoo.com*1
}

\begin{abstract}
Abstrak
Selama proses persalinan hampir sebagian besar ibu bersalin mengalami nyeri, yang membedakannya adalah tingkat nyerinya, ada yang benar-benar merasakan sakit yang luar biasa, namun juga banyak yang tidak terlalu lama. Hal ini banyak faktor penyebabnya, dimulai dari keletihan, stres, cemas dan tegang selama kontraksi. Tujuan penelitian ini untuk mengetahui Pengaruh Pemberian Kompres Hangat Terhadap Penurunan Rasa Nyeri Persalinan Kala I Fase Aktif Di Bidan Praktik Mandiri (BPM) Yulia Fonna SKM Kecamatan Jeumpa Kabupaten Bireuen Tahun 2019.

Desain yang digunakan adalah Preexperimental design dengan pendekatakan one group pretest posttest. Penelitian ini dilakukan pada Mei - Juni 2019. Populasi dalam penelitian ini adalah seluruh ibu bersalin kala I Fase aktif yang mengunjungi BPM. Teknik pengambilan sampel dalam penelitian ini dilakukan dengan metode quota sampling dengan jumlah responden 30 orang di BPM Yulia Fonna. Teknik analisa data univariat menggunakan distribusi frekuensi dan analisa bivariat menggunakan uji wilcoxon.

Hasil pengolahan data diperoleh nilai p value $(0.000)<\alpha(0,05)$. Hasil ini menunjukkan adanya pengaruh penggunaan kompres hangat terhadap penurunan rasa nyeri persalinan kala I fase aktif. Adapun hasil analisa bivariat menunjukkan bahwa dari 30 responden, 27 diantaranya mengalami penurunan rasa nyeri, 3 responden lainnya memiliki skala nyeri sama baik sebelum maupun sesudah intervensi.

Diharapkan untuk tempat penelitian agar lebih memperhatikan kebutuhan ibu bersalin akan rasa nyaman, penerapan kompres hangat ini dapat dijadikan pertimbangan bagi bidan dalam memberikan asuhan sayang ibu agar dapat mengurangi tingkat nyeri dan rasa sakit dalam menghadapi persalinan.
\end{abstract}

Kata kunci: Kompres Hangat, Rasa Nyeri, Persalinan. 
Journal of Healthcare Technology and Medicine Vol. 5 No. 2 Oktober 2019

Universitas Ubudiyah Indonesia

e-ISSN : 2615-109X

\begin{abstract}
During the maternity process most of women have the experience pain, which distinguishes it is the pain level, there are those who really feel tremendous pain, but also many that are not too long. This causes many factors, starting from fatigue, stress, anxiety and tension during contractions. The purpose of this research was to determine the effect of giving a warm compress to the reduction of pain in maternal stage I of active phase in the independent practice midwife (BPM) Yulia Fonna SKM Jeumpa Regency Bireuen District in 2019.

The type of the research is experimental design with one group pretest posttest approuch. This research was conducted on May-Juny 2019. The population in this research were all mothers giving birth stage I of active phase who visited the BPM. The sampling technique in this research used quota sampling method with 30 respondents in Yulia Fonna's BPM. Univariate analysis techniques used frequency distribution and bivariate analysis used the Wilcoxon test.

Based on the results of data processing obtained $p$ value $(0.000)<\alpha(0.05)$. These results indicate there was the effect of using warm compress to the reduction of pain in maternal stage I of active phase. The results of bivariate analysis showed that out of 30 respondents, 27 of them experienced a reduction in pain, 3 other respondents had the same scale of pain both before and after the intervention.

It is hoped that for research sites to pay more attention to maternal needs for comfort, the application of warm compresses can be used as a consideration for midwives in providing maternal care to reduce the level of pain and pain in maternity.
\end{abstract}

Keywords: Risk Factors, Age, Age of Menarche, Parity, Family History.

\title{
PENDAHULUAN
}

Menurut Prawirohardjo (2002) persalinan dan kelahiran normal adalah proses pengeluaran janin yang terjadi pada kehamilan cukup bulan (37-42 minggu), lahir spontan dengan presentasi belakang kepala yang berlangsung dalam 18 jam, tanpa komplikasi baik pada ibu maupun pada janin. Pada persalinan terkadang dapat menimbulkan trauma pada ibu karena nyeri yang dialaminya. Beberapa ibu bahkan ada yang trauma untuk hamil dan melahirkan lagi karena takut akan mengalami nyeri yang sama. Bagi ibu yang pernah melahirkan, nyeri persalinan merupakan nyeri yang paling menyakitkan apalagi bagi ibu-ibu yang baru pertama kali merasakannya (Trirestuti, 2018).

Data WHO 2018, lebih dari 140 juta wanita melahirkan setiap tahun. Walaupun demikian, pada beberapa kasus kelahiran bukanlah peristiwa membahayakan tetapi menjadi suatu masa yang penuh dengan rasa nyeri, rasa takut, penderitaan bahkan kematian, hal inilah yang menyebabkan banyaknya permintaan untuk melakukan sectio caesaria (SC) (Trirestuti, 2018).

Komunitas layanan kesehatan internasional telah mempertimbangkan tingkat ideal untuk operasi caesar antara 10-15\%. Sejak itu, operasi caesar menjadi semakin umum di 
Journal of Healthcare Technology and Medicine Vol. 5 No. 2 Oktober 2019

Universitas Ubudiyah Indonesia

e-ISSN : 2615-109X

negara maju dan berkembang. Pernyataan WHO yang diterbitkan pada tahun 2015 mengatakan bahwa ketika tingkat operasi caesar naik menuju 10\% di seluruh populasi, jumlah kematian ibu dan bayi baru lahir menurun. Ketika angka ini di atas $10 \%$ tidak ada bukti bahwa angka kematian membaik. Di seluruh populasi, efek dari tingkat operasi caesar pada hasil ibu dan bayi baru lahir seperti kelahiran mati atau morbiditas seperti asfiksia lahir masih belum diketahui. Maka WHO menganjurkan bahwa operasi caesar hanya boleh dilakukan jika secara medis diperlukan. Oleh sebab itu sebagai bidan kita harus melakukan upaya untuk mengurangi rasa nyeri sehingga kejadi SC tanpa indikasi bisa dikurangi.

Berdasarkan data yang diperoleh dari Profil kesehatan Indonesia tahun 2017, terdapat 5.082.537 ibu bersalin di Indonesia. Sedangkan di Aceh tercatat 122.421 ibu bersalin, dengan Kabupaten Bireuen jumlah persalinan yang ditolong oleh tenaga kesehatan berjumlah 8.590 orang (Dinkes Kabupaten Bireuen 2018).

Pada saat kala I persalinan, rasa nyeri muncul disebabkan karena adanya dilatasi serviks dan segmen uterus bawah, dengan distensi lanjut, peregangan, dan trauma pada serat otot dan ligamen yang menyokong struktur ini. Rangsangan persalinan kala I ditransmisikan dari serat aferen melalui pleksus hipogastrik superior, inferior dan tengah, rantai simpatik torakala bawah, lumbal ke ganglia akar saraf posterior. Nyeri dapat disebar dari area pelvik ke umbilikus, paha atas dan area midsakral. Intensitas yang dialami pada kontraksi dikaitkan dengan derajat dan kecepatan dilatasi serviks dan segmen uterus bawah, dimana ketika persalinan mengalami kemajuan, intensitas setiap kontraksi meningkat, menghasilkan intensitas nyeri yang lebih besar (Padila, 2014).

Sebenarnya rasa nyeri diperlukan untuk mengenali adanya kontraksi uterus selama proses persalinan, tetapi kadang rasa nyeri tersebut bisa menimbulkan akibat patologis yang dirasakan terus menerus, ditambah rasa cemas dan ketakutan yang dialami ibu bersalin. Hal ini dapat mengakibatkan keletihan sehingga mengakibatkan penurunan kontraksi uterus dan proses persalinan pun berlangsung lebih lama. Persalinan yang lama (prolonged labor) dapat membahayakan ibu dan janin (Rahman, 2017).

Sensasi nyeri yang dirasakan ibu hamil akan berbeda kadarnya, ada yang benar-benar merasakan sakit yang luar biasa, namun juga banyak merasa nyeri yang tidak terlalu lama. Tentunya hal ini banyak faktor penyebabnya, dimulai dari tindakan dokter/bidan dalam menolong persalinan, partus lama, ibu melahirkan tanpa pendamping, keletihan, tidak siap melahirkan, stres, cemas dan tegang selama kontraksi (Trirestuti, 2018). 
Nyeri adalah hal yang lumrah dalam persalinan. Tetapi apabila tidak diatasi dengan baik akan menimbulkan masalah lain yaitu meningkatnya kecemasan atau rasa khawatir karena dan mengakibatkan vasokonstriksi yang menyebabkan aliran darah ibu ke janin menurun. Pelepasan hormon seperti katekolamin dan steroid yang berlebihan menyebabkan terjadinya ketegangan otot polos dan vasokonstriksi pembuluh darah. Sehingga dapat mengakibatkan penurunan kontraksi uterus, penurunan sirkulasi uteroplasenta, pengurangan aliran darah dan oksigen ke uterus, serta timbulnya iskemia uterus yang membuat impuls nyeri bertambah banyak (Juniartati, 2018).

Pemberian asuhan pelayanan harus memperhatikan kenyamanan ibu yang akan melahirkan, salah satunya adalah penanganan nyeri persalinan. Penolong persalinan seringkali melupakan untuk menerapkan teknik pengontrolan nyeri, hal ini akan menyebabkan ibu bersalin memiliki pengalaman persalinan yang buruk, mengalami trauma persalinan yang dapat menyebabkan postpartum blues, maka sangat penting untuk penolong persalinan memenuhi kebutuhan ibu akan rasa aman dan nyaman (Juniartati, 2018).

Upaya untuk menurunkan nyeri pada persalinan dapat dilakukan baik secara farmakologi maupun non farmakologi. Cara menghilangkan sakit persalinan secara farmakologi adalah dengan pemberian analgetik obat pereda sakit, suntikan epidural, blok saraf perineal dan pudendal, menggunakan mesin Transcutaneous Electrical Nerve Stimulation (TENS) untuk merangsang tubuh memproduksi senyawa penghilang rasa sakit. Secara non farmakologis penatalaksanaannya antara lain dengan menghadirkan pendamping persalinan, perubahan posisi dan pergerakan, sentuhan dan massage, hipnotis, kompres hangat dan dingin, berendam di air hangat, terapi akupuntur, visualisasi dan pemusatan perhatian dan musik (Trirestuti, 2018).

Manajemen nyeri secara farmakologi lebih efektif dibanding dengan metode non farmakologi, namun metode farmakologi lebih mahal, dan berpotensi mempunyai efek samping yang kurang baik. Sedangkan metode non farmakologi lebih murah, simpel, efektif dan tanpa efek yang merugikan dan dapat meningkatkan kepuasan selama persalinan, karena ibu dapat mengontrol perasaannya dan kekuatannya (Juniartati, 2018).

Salah satu penelitian terkait dengan fenomena nyeri persalinan non farmakologis yang dilakukan oleh Xaverini tentang "Pengaruh pemberian kompres hangat terhadap intensitas nyeri persalinan kala I fase aktif pada ibu di Rumah Sakit Umum Dewi Sartika Kota Kendari Provinsi Sulawesi Tenggara", dengan hasil penelitian bahwa ada pengaruh pemberian 
Journal of Healthcare Technology and Medicine Vol. 5 No. 2 Oktober 2019

Universitas Ubudiyah Indonesia

e-ISSN : 2615-109X

kompres hangat terhadap intensitas nyeri persalinan kala I fase aktif, dengan nilai rata-rata intensitas nyeri persalinan kala I fase aktif sebelum diberi kompres hangat yaitu $8,2 \pm 0,67$, sedangkan nilai rata-rata intensitas nyeri persalinan kala I fase aktif sesudah diberi kompres hangat yaitu $6,2 \pm 0.67$ dengan $p=0,000$, sehingga disimpulkan bahwa terjadi penurunan intensitas nyeri setelah diberikan kompres hangat (Xaverini, 2017).

Kompres air hangat yang diberikan pada punggung bawah wanita di area tempat kepala janin menekan tulang belakang, panas akan meningkatkan suhu kulit lokal, mengurangi spasme otot dan mengurangi nyeri. Panas dapat disalurkan melalui handuk basah hangat, bantalan panas, kantong pasta silika yang dipanaskan, atau botol air panas (Johariyah, 2012).

Berdasarkan hasil studi pendahuluan pada bulan Mei 2019 di Bidan Praktek Mandiri (BPM) Yulia Fonna, Desa Lipah Rayeuk Kabupaten Bireuen diperoleh data ibu bersalin dari bulan Januari sampai Februari 2019 sebanyak 43 orang (BPS Yulia Fonna, 2019).

Pada survei awal yang dilakukan pada bulan Mei di BPM Yulia Fonna pada ibu bersalin didapati yang menjadi keluhan utama ibu dengan persalinan inpartu kala I adalah nyeri. Hal ini sesuai dengan teori yang mengatakan bahwa nyeri persalinan kala I mucul karena adanya kontraksi otot-otot uterus, peregangan serviks dan segmen bawah rahim dimana intensitas nyeri meningkat seiring dengan kemajuan persalinan.

Berdasarkan uraian tersebut dan mengingat pentingnya memberikan rasa nyaman atas rasa nyeri agar tidak terjadi penyulit selama persalinan dan mudahnya teknik kompres hangat, maka penulis tertarik untuk melakukan penelitian tentang pengaruh pemberian kompres hangat terhadap penurunan rasa nyeri persalinan kala I fase aktif pada ibu bersalin di BPM Yulia Fonna.

\section{METODE PENELITIAN}

Desain penelitian yang digunakan adalah Preeksperimental design dengan pendekatan one group pretest posttest yaitu rancangan penelitian yang dilakukan dengan cara memberikan pretest (pengamatan awal) terlebih dahulu sebelum diberikan intervensi. Setelah diberikan intervensi, kemudian dilakukan posttest (pengamatan akhir) (Hidayat,2014). Bentuk rancangan penelitian ini adalah sebagai berikut (Notoatmodjo, 2012). 


\begin{tabular}{|rcl|}
\hline Pretest & Perlakuan & Posttest \\
\hline 01 & $\mathrm{X}$ & 02 \\
\hline
\end{tabular}

Gambar 1. Rancangan One Group Pretest Posttest

Lokasi penelitian adalah tempat dimana penelitian dilaksanakan (Iman, 2016).Penelitian ini dilakukan di BPM Yulia Fonna Desa Lipah Rayeuk Kecamatan Jeumpa Kabupaten Bireuen. Populasi adalah jumlah keseluruhan subjek penelitian (Notoadmodjo, 2012). Penelitian ini dilaksanakan pada Mei- Juni 2019 Mei Populasi dalam penelitian ini adalah seluruh ibu inpartu kala I fase aktif di BPM Yulia Fonna Desa Lipah Rayeuk Kecamatan Jeumpa Kabupaten Bireuen.

Jenis data yang di gunakan Data primer dan data sekunder. Teknik analisa data univariat menggunakan distribusi frekuensi dan analisa bivariat menggunakan uji wilcoxon.

\section{HASIL PENELITIAN}

Analisis Univariat digunakan untuk mengetahui distribusi frekuensi tentang pengaruh pemberian kompres hangat terhadap penurunan rasa nyeri.

\section{A. Intensitas Nyeri Sebelum Pemberian Kompres Hangat}

Tabel 1. Distribusi Frekuensi Intensitas Nyeri Sebelum Diberikan Kompres Hangat Pada Ibu Bersalin Kala I Fase Aktif di BPM Yulia Fonna Desa Lipah Rayeuk Kecamatan Jeumpa Kabupaten Bireuen Tahun 2019.

\begin{tabular}{clcc}
\hline \multirow{2}{*}{ NO } & \multicolumn{1}{c}{$\begin{array}{c}\text { Skala Nyeri } \\
(\text { Pretest })\end{array}$} & F & Jumlah \\
\cline { 3 - 4 } & Ringan & 0 & \% \\
2 & Sedang & 19 & 63,3 \\
3 & Berat & 9 & 30,0 \\
4 & Sangat berat & 2 & 6,7 \\
\hline & Jumlah & $\mathbf{3 0}$ & $\mathbf{1 0 0}$ \\
\hline
\end{tabular}

Sumber : Data Primer (Diolah tahun 2019)

Berdasarkan tabel 1. didapatkan hasil bahwa mayoritas responden memiliki skala nyeri sedang yaitu sebanyak 19 orang $(63,3 \%)$ dan minoritas responden memiliki skala nyeri sangat berat yaitu sebanyak 2 orang $(6,7 \%)$. 


\section{B. Intensitas Nyeri Setelah Pemberian Kompres Hangat}

Tabel 2. Distribusi Frekuensi Intensitas Nyeri Setelah Diberikan Kompres Hangat Pada Ibu Bersalin Kala I Fase Aktif di BPM Yulia Fonna Desa Lipah Rayeuk Kecamatan Jeumpa Kabupaten Bireuen Tahun 2019.

\begin{tabular}{cccc}
\hline \multirow{2}{*}{ NO } & $\begin{array}{c}\text { Skala Nyeri } \\
\text { (Posttest) }\end{array}$ & F & Jumlah \\
\hline 1 & Ringan & 19 & 63,3 \\
2 & Sedang & 6 & 20,0 \\
3 & Berat & 5 & 16,7 \\
4 & Sangat berat & 0 & 0 \\
\hline & Jumlah & $\mathbf{3 0}$ & $\mathbf{1 0 0}$ \\
\hline
\end{tabular}

Sumber : Data Primer (Diolah tahun 2019)

Berdasarkan tabel 2. maka didapatkan hasil bahwa mayoritas responden memiliki skala nyeri ringan yaitu sebanyak 19 responden $(63,3 \%)$ dan minoritas responden memiliki skala nyeri berat yaitu sebanyak 5 orang $(16,7 \%)$.

Analisis Bivariat digunakan untuk mengetahui hubungan antara variabel independen terhadap variabel dependen dengan menggunakan chi-square pada tingkat kemaknaan 95\% atau nilai $(\alpha=0,05)$. Bila menunjukan nilai $\mathrm{p} \leq 0,05$ artinya ada hubungan bermakna atau signifikan.

Tabel 3. Pengaruh Pemberian Kompres Hangat Terhadap Penurunan Rasa Nyeri Persalinan kala I Fase Aktif di BPM Yulia Fonna Desa Lipah Rayeuk Kecamatan Jeumpa Kabupaten Bireuen Tahun 2019.

\begin{tabular}{|c|c|c|c|c|c|c|c|c|}
\hline Variabel & Intervensi & & $\mathbf{N}$ & $\begin{array}{l}\text { Mean } \\
\text { Rank }\end{array}$ & $\begin{array}{c}\text { Sum of } \\
\text { Rank }\end{array}$ & $\mathbf{Z}$ & $\begin{array}{c}P \\
\text { Value }\end{array}$ & $\alpha$ \\
\hline \multirow{4}{*}{$\begin{array}{c}\text { Penurunan } \\
\text { rasa nyeri } \\
\text { persalinan } \\
\text { kala I fase } \\
\quad \text { aktif }\end{array}$} & \multirow{4}{*}{$\begin{array}{l}\text { Sebelum- } \\
\text { sesudah }\end{array}$} & $\begin{array}{c}\text { Negatif } \\
\text { Ranks }\end{array}$ & $27^{\mathrm{a}}$ & 14,00 & 378,00 & \multirow{4}{*}{$-5,196$} & \multirow{4}{*}{0,000} & \multirow{4}{*}{0,05} \\
\hline & & $\begin{array}{l}\text { Positif } \\
\text { Ranks }\end{array}$ & $0^{\mathrm{b}}$ & 0,00 & 0,00 & & & \\
\hline & & Ties & $3^{c}$ & & & & & \\
\hline & & Jumlah & 30 & & & & & \\
\hline
\end{tabular}

Sumber : Data Primer (Diolah tahun 2019)

Berdasarkan tabel 3. dapat diketahui bahwa nilai $\mathrm{N}$ pada negatif rank yaitu 27 yang artinya ke 27 responden mengalami penurunan rasa nyeri dengan nilai mean rank atau ratarata penurunannya yaitu sebesar 14,00 dan sum of rank atau ranking negatifnya adalah 378,000. Pada nilai positif rank menunjukkan nilai $\mathrm{N} 0$ baik nilai mean rank maupun sum of rank yang artinya tidak ada responden yang mengalami peningkatan skala nyeri setelah intervensi. Sedangkan pada nilai $\mathrm{N}$ ties terdapat 3 responden yang artinya ada responden yang memiliki skala nyeri yang sama baik sebelum maupun sesudah intervensi. 
Journal of Healthcare Technology and Medicine Vol. 5 No. 2 Oktober 2019

Universitas Ubudiyah Indonesia

e-ISSN : 2615-109X

Berdasarkan analisa statistik menggunakan uji wilcoxon, di dapat nilai $p$ value $(0,000)$ $<\alpha(0,05)$ maka Ha diterima dan Ho ditolak dengan demikian dapat disimpulkan bahwa ada pengaruh kompres hangat terhadap penurunan rasa nyeri persalinan kala I fase aktif di BPM Yulia Fonna Desa Lipah Rayeuk Kecamatan Jeumpa kabupaten Bireuen Tahun 2019.

\section{PEMBAHASAN}

\section{Pengaruh Pemberian Kompres Hangat Terhadap Penurunan Rasa Nyeri}

Berdasarkan penelitian dengan melakukan analisa tentang pengaruh penggunaan kompres hangat terhadap penurunan rasa nyeri di BPM Yulia Fonna, di temukan hasil bahwasanya dari 30 responden terdapat 27 responden yang mengalami penurunan skala nyeri setelah diberikan kompres hangat, dimana 3 responden diantaranya tidak mengalami perubahan skala nyeri baik sebelum maupun sesudah diberi kompres hangat. Berdasarkan dari hasil yang didapatkan tersebut kita bisa melihat dan membandingkan bahwasanya jumlah responden dengan penurunan skala nyeri lebih banyak setelah dilakukan pengompresan dibandingkan dengan yang tidak mengalami perubahan skala nyeri yang hanya berjumlah 3 responden, sehingga dapat dikatakan bahwa ada pengaruh pemberian kompres hangat terhadap penurunan skala nyeri.

Berdasarkan hasil analisa statistik menggunakan uji wilcoxon, di dapat nilai $\mathrm{p}$ value $(0,000)<\alpha(0,05)$ sehingga didapatkan hasil penelitian bahwa ada pengaruh kompres hangat terhadap penurunan rasa nyeri persalinan kala I fase aktif di BPM Yulia Fonna Desa Lipah Rayeuk Kecamatan Jeumpa kabupaten Bireuen Tahun 2019. Hasil penelitian ini sesuai dengan hasil penelitian yang dilakukan oleh Xaverini (2017) tentang "Pengaruh pemberian kompres hangat terhadap intensitas nyeri persalinan kala I fase aktif pada ibu di Rumah Sakit Umum Dewi Sartika Kota Kendari Provinsi Sulawesi Tenggara”, dengan hasil penelitian bahwa ada pengaruh pemberian kompres hangat terhadap intensitas nyeri persalinan kala I fase aktif, dengan nilai rata-rata intensitas nyeri persalinan kala I fase aktif sebelum diberi kompres hangat yaitu 8,2 $\pm 0,67$, sedangkan nilai rata-rata intensitas nyeri persalinan kala I fase aktif sesudah diberi kompres hangat yaitu 6,2 \pm 0.67 dengan nilai p value $(0,000)<\alpha(0,05)$.

Hasil penelitian ini juga diperkuat dengan hasil penelitian yang dilakukan oleh Fitrianingsih tahun 2017, dengan judul "Pengaruh Kompres Hangat Terhadap Rasa Nyeri Persalinan Kala I Fase Persalinan Fase Aktif di 3 BPM Kota Cirebon". Dengan nilai Asym.Sig (nilai p) sebesar 0,000. Hal ini menunjukkan bahwa nilai $p<0,05$ jadi dapat 
Journal of Healthcare Technology and Medicine Vol. 5 No. 2 Oktober 2019

Universitas Ubudiyah Indonesia

e-ISSN : 2615-109X

diambil kesimpulan bahwa ada pengaruh kompres hangat terhadap penurunan rasa nyeri persalinan kala I fase aktif.

Hasil penelitian lainnya juga dilakukan oleh oleh Wulandari tahun 2016, dengan judul "Pengaruh Pemberian Kompres Hangat Terhadap Intensitas Nyeri pada Ibu Bersalin Kala I Fase Aktif di RB. Mardi Rahayu Semarang”. Berdasarkan hasil penelitian yang diperoleh yaitu sebelum dilakukan intervensi pemberian kompres hangat sebesar 15 responden mengalami nyeri sekali dan setelah dilakukan intervensi pemberian kompres hangat 14 responden mengalami nyeri sedikit. Setelah dianalisis menggunakan uji wilcoxon di dapati hasil $\mathrm{p}$ value 0,000 dengan taraf dan dapat disimpulkan $\mathrm{p}$ value $\leq 0,05$ dengan demikian dikatakan ada pengaruh pemberian kompres hangat terhadap intensitas nyeri pada ibu bersalin kala I fase aktif di RB. Mardi Rahayu Semarang.

Dari hasil penelitian tersebut terdapat perbedaan yang signifikan pada rasa nyeri sebelum dan sesudah diberikan kompres hangat, dikarenakan manfaat dari kompres hangat yang dapat memberikan rasa nyaman pada ibu.

Menurut asumsi peneliti kompres hangat yang diberikan pada punggung bagian bawah ibu di area tempat kepala janin menekan tulang belakang, efek panas yang dsalurkan melalui kompres hangat dapat mengurangi rasa nyeri dengan memperlancar sirkulasi darah, mengurangi kekakuan otot sehingga ibu dapat merasakan rasa nyaman dan membantu mengurangi rasa sakit saat permulaan persalinan. Secara keseluruhan berdasarkan apa yang telah peneliti observasi, semua responden rata-rata mengatakan bahwa nyeri persalinan yang dirasakannya berkurang dan merasa lebih nyaman walaupun respon yang diberikannya berbeda-beda.

\section{KESIMPULAN}

Kesimpulan peneliti ini ada pengaruh pemberian kompres hangat terhadap penurunan rasa nyeri persalinan kala I fase aktif diperoleh hasil nilai p value $(0,000)<\alpha(0,05)$, maka Ha diterima Ho ditolak dan dapat disimpulkan bahwa ada pengaruh pemberian kompres hangat terhadap penurunan rasa nyeri persalinan kala I fase aktif di BPM Yulia SKM Fonna Desa Lipah Rayeuk Kecamatan Jeumpa Kabupaten Bireuen Tahun 2019.

\section{SARAN}


Journal of Healthcare Technology and Medicine Vol. 5 No. 2 Oktober 2019

Universitas Ubudiyah Indonesia

e-ISSN : 2615-109X

Diharapkan kepada responden agar hasil penelitian ini dapat digunakan sebagai bahan masukan dalam menambahkan pengetahuan tentang pentingnya terapi kompres hangat terhadap penurunan intensitas nyeri khususnya pada ibu bersalin saat menghadapi permulaan persalinan.

\section{DAFTAR PUSTAKA}

Asrinah, Putri SS, Sulistyorini D, Muflihah IS, Sari DN. (2010). Asuhan Kebidanan. Yogyakarta: Graha Ilmu.

Bakara DM, Lagora R, Farizal J. (2013). Pengaruh Kompres Hangat Kering Pada Nyeri Persalinan Primipara Kala I Fase Aktif. Jurnal Kesehatan Poltekes Pontianak.

Devi TER, Sulastriningsih K, Tiawaningrum E. (2018). Pengaruh Yoga Prenatal dan Hybnobirthing Terhadap Proses persalinan Kala I Pada Ibu Bersalin di BPM Restu Depok Periode Januari-Juni Tahun 2017. Jurnal Stikes Nani Hasanuddin Makasar.

Felina M, Masrul, Iryani D. (2015). Pengaruh Kompres Panas dan Dingin terhadap Penurunan Nyeri Kala I Fase Aktif Persalinan Fisiologi Ibu Primipara. Jurnal Fakultas kedokteran Unand.

Fitrianingsih Y, Wandani K. (2018). Pengaruh kompres Hangat Terhadap Rasa Nyeri Persalinan Kala I Fase Persalinan Fase Aktif di BPM Kota Cirebon. Jurnal Kesehatan Unitri.

Hidayat, AA. (2014). Metode Penelitian Kebidanan dan teknik Analisis Data. Jakarta Selatan: Salemba Medika.

Iman, M. (2012). Pemanfaatan SPSS Dalam Penelitian Bidang Kesehatan. Bandung: Citapustaka Media Perintis.

Iman, M. (2016). Panduan Penyusunan Karya Tulis Ilmiah Bidang Kesehatan Menggunakan Metodelogi Penelitian Ilmiah. Bandung: Citapustaka Media Rintis.

Johariyah, Ningrum EW. (2012). Asuhan Kebidanan Persalinan dan Bayi Baru Lahir. Jakarta Timur: CV. Trans Info Media.

Juniartati E, Widyawati MN. (2018). Literature Reviev:Penerapan Counter Pressure Untuk Mengurangi Nyeri Persalinan Kala I. Jurnal Kesehatan Poltekes Semarang

Notoatmodjo, S. (2012). Metodologi Penelitian Kesehatan. Jakarta: Rineka Cipta.

Padila. (2014). Keperawatan Maternitas. Yogyakarta: Nuha Medika. 
Journal of Healthcare Technology and Medicine Vol. 5 No. 2 Oktober 2019

Universitas Ubudiyah Indonesia

e-ISSN : 2615-109X

Rahman SA, Handayani A, Sumarni, Mallongi A. (2017). Penurunan Nyeri Persalinan Dengan kompres Hangat dan Massage Effleurage. Jurnal Kesehatan Universitas Hasanuddin

Rohan HH, Siyoto S. (2013). Kesehatan Reproduksi. Yogyajakarta: Nuha Medika.

Sari EP, Rimandini KD. (2014). Asuhan Kebidanan Persalinan (intranatal Care). Jakarta Timur: CV. Trans Info Media.

Sulistyowati WWD, Sari IRT. (2018). Efektifitas Kompres Hangat Terhadap Sensasi Rasa Nyeri Pada Kala I Fase Aktif Ibu Primigravida. Jurnal Universitas Adi Buana Surabaya.

Trirestuti C, Puspitasari D. (2018). Asuhan Kebidanan 2. Jakarta Timur: CV. Trans Info Media.

World Health Organization (WHO). (2018). Making childbirth a positive experience. Situs Human Reproduction Programme.

Wulandari P, Kustriyani M, Chasanah U. (2016). Pengaruh Pemberian Kompres Hangat Terhadap Intensitas Nyeri Pada Ibu Bersalin kala I Fase Aktifei RB. Mardi Rahayu Semarang. Jurnal Kesehatan Universitas Muhammadiah Semarang. 